\title{
Treatment of COPD: the sooner the better?
}

\author{
Marc Decramer, ${ }^{1}$ Christopher B Cooper ${ }^{2}$
}

${ }^{1}$ Respiratory Division, University of Leuven, Belgium ${ }^{2}$ Respiratory Division, David Geffen School of Medicine, University of California, Los Angeles, USA

\section{Correspondence to}

Marc Decramer, Respiratory Division, University Hospital, Herestraat 49, 3000 Leuven, Belgium;

marc.decramer@uzleuven.be

Received 16 December 2009 Accepted 11 May 2010

\section{ABSTRACT}

Classical belief is that only smoking cessation, and not pharmacotherapy, beneficially affect disease progression in chronic obstructive pulmonary disease (COPD). In recent years, new data on pharmacotherapy of COPD became available that shed new light on this question. The present paper reviews these data critically in an attempt to put them in a proper perspective. The most impressive new data are subgroup analyses of two large-scale long-term trials. With these new data it is now clear that patients in GOLD (Global Initiative for Chronic Obstructive Pulmonary Disease) stage II benefit as much from pharmacotherapy as patients in the later stages of the disease. Effects on prebronchodilator and postbronchodilator forced expiratory volume in $1 \mathrm{~s}$ $\left(F_{E V}\right)$, health-related quality of life, exacerbations and hospitalisations appear at least as pronounced in GOLD stage II as in the other GOLD stages. In addition, evidence suggestive of an effect on disease progression is available in the sense of an effect on rate of decline of $\mathrm{FEV}_{1}$, and trends for reductions in mortality. Finally, good evidence is available that, in contrast to conventional thinking, decline of FEV ${ }_{1}$ occurs at a considerably faster rate in the early stages of the disease. These data together with the high prevalence of co-morbidities from early in the disease onwards provide us with strong suggestive evidence for early intensive intervention in COPD. New trials, particularly demonstrating the detrimental effects of delaying treatment until later in the course of the disease, are required to render the evidence for early intensive intervention irrefutable.

\section{INTRODUCTION}

Chronic obstructive pulmonary disease (COPD) is a highly prevalent disease affecting $>10 \%$ of the population worldwide. ${ }^{1}$ Typically, the disease presents in the fourth or fifth decade with subtle symptoms such as morning cough productive of mucoid sputum or simply an insidious progression of exertional dyspnoea. However, the disease runs a prolonged course and undoubtedly starts earlier in life following classical epidemiological principles of genetic predisposition, an induction period before exposure to inhaled particulates or fumes, and latency prior to disease onset. Progression of the disease has proved difficult to characterise, but can be envisaged schematically in figure 1 . The first manifestations occur at the cellular level with biochemical processes that lead to inflammation. Probably the earliest structural changes associated with COPD, including reduced lung density and airway wall thickening, can now be detected by high-resolution chest $\mathrm{CT}^{2}{ }^{3}$ However, even these structural changes may not be accompanied by measurable physiological impairments until later in the progression of the disease. Evidence suggests that airflow obstruction and dynamic hyperinflation (or failure to reduce end-expiratory lung volume during exercise) are the earliest detectable physiological impairments. However, these features are often not accompanied by symptoms that are readily appreciated or reported by patients. Historically, disease progression in COPD has been defined by an accelerated decline in forced expiratory volume in $1 \mathrm{~s}\left(\mathrm{FEV}_{1}\right)$, but this is a crude measure of airway function whose relevance is uncertain in the schematic represented in figure 1. Probably an accelerated decline in exercise performance accompanies the decline in pulmonary function, ${ }^{4}$ although there is limited published evidence, at present, to support this concept ${ }^{5}$; hence the challenge of identifying COPD early in its clinical course and characterising its progression.

For a long period of time, smoking cessation was the only treatment affecting the progression of the disease in the sense that it was shown to reduce the rate of decline of $\mathrm{FEV}_{1}{ }^{6}$ and mortality. ${ }^{7}$ Pharmacotherapy for COPD, however, has improved substantially in the last decade. The availability of long-acting $\beta$-agonists (LABAs), fixed combinations of inhaled cortisteroids and LABAs, and long-acting anticholinergics or muscarinic antagonists (LAMAs) has allowed improved outcomes in these patients substantially more than was possible before. As exacerbations are thought to be related to $\mathrm{FEV}_{1}$ decline $^{89}$ and the aforementioned drugs all reduce the exacerbation rate, an effect on the progression of the disease may be expected. Indeed, in recent large-scale studies, evidence was obtained that was at least strongly suggestive of the aforementioned medications affecting COPD progression. In the TORCH study, a trend for reduced mortality was observed with the use of the fixed combination of salmeterol and fluticasone. ${ }^{10}$ In a posthoc analysis, LABAs, inhaled steroids and the fixed combination of these drugs were shown to reduce the annual rate of decline of $\mathrm{FEV}_{1}$ by 13,13 and $16 \mathrm{ml}$, respectively. ${ }^{9}$ In the UPLIFT study, an effect of tiotropium on the rate of decline of $\mathrm{FEV}_{1}$ was suspected in patients who did not take concomitant medication (see below). ${ }^{11} 12$ In addition, evidence of a reduced mortality rate was found. ${ }^{11}$ These recent large-scale studies therefore challenge the classical concept, which was largely based on inhaled corticosteroid studies, ${ }^{13-16}$ that medical treatment does not affect the progression of the disease in COPD.

In the light of these results, it appears timely, once again, to ask two important questions. Should we treat patients with COPD with medications earlier than we presently do? Should patients even be detected systematically for earlier treatment? These relevant questions are the subject of the present perspective. We will first review the 


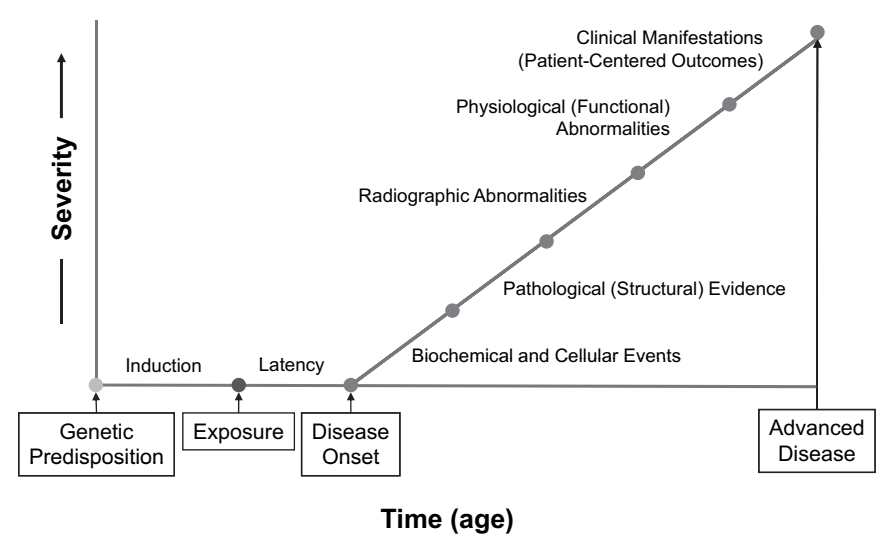

Figure 1 Conceptual diagram of disease progression in chronic obstructive pulmonary disease (COPD).

evidence accumulated in recent years on early treatment of COPD, then we will address the implications of this evidence for progressive loss of pulmonary function in COPD and the implications for early treatment and future research needs.

\section{EVIDENCE ACCUMULATED ON EARLY TREATMENT OF COPD IN RECENT YEARS}

There is probably a widely held opinion at present that there is no irrefutable evidence that early treatment of COPD is better than later treatment. Conceptually, irrefutable evidence would probably emerge from a study that is schematically outlined in figure 2. This would be a study in which patients would be detected in general practice by screening or case-finding procedures which would consist of performing spirometry in all patients who are at risk for the development of COPD. Subsequently, these patients would then need to be randomised into a group receiving early intensive treatment and a group receiving treatment for symptoms only. The study would need to last for $1-2$ years. If a difference between the two groups were present after 2 years, it would still not irrefutably prove the benefits of early detection. What would be then be required would be to demonstrate that if intensive treatment were now also given to patients who previously received treatment only for symptoms, these patients would never reach the same level in outcomes as the patients who received intensive treatment earlier (solid line in figure 2 instead of dashed line). The latter element would irrefutably make the case for early treatment. Obviously costeffectiveness considerations would need to be taken into account as well. For example, the cost of prolonged maintenance treatment would need to be weighed against proven cost-beneficial outcomes such as preventing exacerbations, which are known to be one of the main drivers of cost in COPD management. Other cost-beneficial outcomes could relate to the prevention of the development of co-morbidities such as those related to diminished physical activity. These are complex questions and, needless to say, such evidence is not available at present. Any evidence that might be available should be regarded as suggestive at best.

Notwithstanding these concerns, in the last few years there has been accumulating suggestive evidence that early treatment might be beneficial. The first relevant question in this context is the definition of early intervention. It is probably fair to say that at present, treatment in patients with COPD is usually started in GOLD (Global Initiative for Chronic Obstructive Pulmonary Disease) stage III-IV-that is, patients with severe disease. The majority of the recent studies of pharmacotherapy

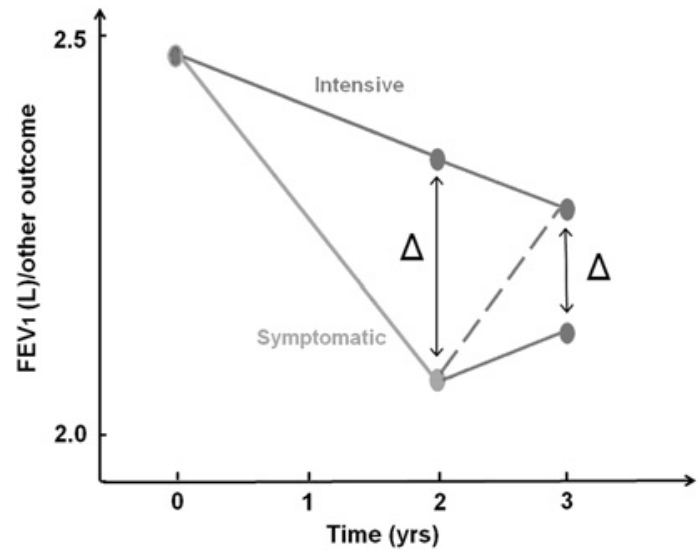

Figure 2 Decline of forced expiratory volume in $1 \mathrm{~s}\left(\mathrm{FEV}_{1}\right)$ or other outcome in a hypothetical study randomising patients into a group receiving early intensive intervention and a group receiving treatment for symptoms only. After 2 years the group that received treatment of symptoms is switched to intensive treatment as well. $\Delta=$ Difference between the two treatment groups. The dashed line and solid line represent two possible evolutions after 2 years.

were performed in patients in the severe category (mean $\mathrm{FEV}_{1}$ $36-45 \%$ predicted). ${ }^{17}$ From our experience of community spirometry testing organised by the Belgian Society of Pneumology, whereby free spirometry was offered for the early detection of COPD in smokers, we know that most of the patients with newly detected COPD fell in GOLD stage II (49\%) versus GOLD stage I (39\%). Hence, it appears logical to define early intervention operationally as an intervention in GOLD stage II. One small-scale study $(n=224)$ examined the effects of tiotropium in patients with GOLD stage II. ${ }^{18}$ The investigators showed that tiotropium improved $\mathrm{FEV}_{1}$ and forced vital capacity (FVC) in patients in GOLD stage II recruited in general practice. Also, analysis of the data from pooled tiotropium trials showed that the bronchodilator effect on FEV- expressed in millilitres, was similar in GOLD stage II, III and IV. This in essence means that improvement of pulmonary function is possible in the early stages of COPD.

Most of the evidence on early treatment presently comes from the recent large-scale studies, TORCH ${ }^{9} 10{ }^{19}$ and UPLIFT. ${ }^{11} 1720$ Although both studies focused in essence on patients with more severe COPD (mean postbronchodilator $\mathrm{FEV}_{1}$ of $44 \%$ and $47 \%$ predicted, respectively), these two studies contained relatively large groups of patients in GOLD stage II and had sufficient power to allow subgroup analysis. The TORCH study included 6112 patients randomised into four treatment groups: LABA, salmeterol; inhaled corticosteroid, fluticasone; fixed combination of the former two medications; and placebo. An analysis of the treatment effects in different GOLD stages was published recently. ${ }^{19}$ A total of 2156 patients fell in GOLD stage II, 3019 in GOLD stage III and 937 in GOLD stage IV. The treatment effects with the fixed combination product in patients in GOLD stage II were as follows: $101 \mathrm{ml}$ improvement in postbronchodilator $\mathrm{FEV}_{1}, 16 \mathrm{ml} /$ year reduction in the annual rate of decline of $\mathrm{FEV}_{1}$, $31 \%$ reduction in exacerbation rate, 2.3 units improvement in SGRO (St George's Respiratory Questionnaire) and 33\% reduction in mortality rate. Except for the improvement in SGRO which was the highest in patients in the more severe stages, all of these improvements were numerically slightly higher in GOLD stage II patients. For none of these treatment effects was a significant treatment by GOLD stage interaction observed, leading to the conclusion that treatment effects on all relevant 
outcomes were present in GOLD stage II and they were at least as significant as in the other GOLD stages.

In another analysis of the rate of decline of $\mathrm{FEV}_{1}$, two observations were made which are of considerable interest in the present context. ${ }^{9}$ First, treatment with the fixed combination product, LABA and inhaled corticosteroid all significantly reduced the rate of decline of $\mathrm{FEV}_{1}$ by $13-16 \mathrm{ml}$, compared with placebo. Within the limits of this analysis-that is accepting that the decline of $\mathrm{FEV}_{1}$ was not the primary end point, that there was differential drop-out during the study and that highly variable rates of decline were observed-these data strongly suggest that treatment with these medications reduces the progression of COPD. If indeed this treatment has the potential of reducing the progression of COPD, then it appears at least intuitively logical that earlier treatment would be better than later treatment. Another observation in this study would further corroborate this contention. Indeed, in the latter analysis, baseline $\mathrm{FEV}_{1}$ was a significant co-variate of decline of $\mathrm{FEV}_{1}$, such that patients with the lowest $\mathrm{FEV}_{1}$ had the lowest rate of decline and patients with the highest $\mathrm{FEV}_{1}$ had the highest rate of decline. This is in accordance with several other studies ${ }^{21} 22$ and appears to contrast with the classical concept put forward by Fletcher and Peto. ${ }^{23}$ In any event, it would again suggest that early intervention would seem intuitively logical.

Two subgroup analysis from the recently published UPLIFT study further support these concepts. The first subgroup analysis dealt with patients in GOLD stage II, which included 2739 of the total of 5993 patients and as such is the largest study on GOLD stage II currently undertaken. ${ }^{17}$ Tiotropium increased prebronchodilator and postbronchodilator $\mathrm{FEV}_{1}$ significantly at all points in time during the trial, with $100-118 \mathrm{ml}$ and 52-81 $\mathrm{ml}$, respectively. In addition, tiotropium significantly reduced the rate of decline of postbronchodilator $\mathrm{FEV}_{1}$ relative to control $(\Delta=6 \mathrm{ml}, \mathrm{p}=0.02)$. Such an effect was not present in the later stages. It should also be taken into account that in this study $\sim 56-59 \%$ of the patients took a combination of inhaled steroids and LABAs, such that the observed effect occurs on top of the effects of these drugs. Health status improved significantly with tiotropium at all points in time, with an effect ranging from 2.7 to 4.0 units, but its rate of deterioration was unaffected by treatment. Exacerbations and hospitalisations were significantly reduced by $18 \%$ and $26 \%$, respectively. These effects occurred in spite of low rates of exacerbations and hospitalisations ( 0.56 and 0.70 per patient year and 0.08 and 0.10 per patient year, respectively). A trend for reduced mortality was present, but did not reach statistical significance.

These treatment effects appear similar to those observed with a fixed combination product in the TORCH study (see above). The effect on rate of decline of $\mathrm{FEV}_{1}$ is of particular interest as it provides hope for an effect on disease progression, albeit small in the present study. In this context another observation made in the UPLIFT study is of considerable interest. The rate of decline in GOLD stage II was clearly greater than in GOLD stage III and IV (control: $49 \mathrm{ml} /$ year vs $38 \mathrm{ml} /$ year and $23 \mathrm{ml} /$ year, respectively). This appears to confirm observations made before (see above) that baseline $\mathrm{FEV}_{1}$ is a determinant of $\mathrm{FEV}_{1}$ decline. If indeed the decline is greatest in the earlier stages of the disease and if it is possible to reduce the rate of decline in earlier stages and not in the later stages, then a good case for early treatment appears to be made.

A second subgroup analysis involving UPLIFT patients who did not take maintenance treatment prior to randomisation further supports this case. ${ }^{12}$ This subgroup analysis contained $\sim 810$ patients or $\sim 400$ per group. The majority of these patients $(60 \%)$ fell in GOLD stage II. The results showed that in patients who were not previously taking maintenance medication, tiotropium clearly reduced the rate of decline of prebronchodilator and postbronchodilator $\mathrm{FEV}_{1}$ (prebronchodilator, 35 vs $45 \mathrm{ml} /$ year, $\mathrm{p}<0.049$; postbronchodilator 42 vs $53 \mathrm{ml} /$ year, $\mathrm{p}<0.026$, respectively). Tiotropium also significantly increased prebronchodilator and postbronchodilator $\mathrm{FEV}_{1}$ at each point in time during the trial (prebronchodilator, 99-160 ml; postbronchodilator, $52-110 \mathrm{ml}$ ). In addition, it significantly improved health-related quality of life $(\Delta=2.3-6.9$ units, $\mathrm{p}<0.001)$. Finally, and importantly, it reduced the rate of decline of health-related quality of life (0.66 units/year vs 1.71 units/ year, $\mathrm{p}<0.002)$. This subgroup analysis provides strong evidence that in patients who did not take maintenance medication at the beginning of the trial, tiotropium slowed progression in the early stages of the disease.

A word of caution is necessary here. Virtually all of the evidence cited here pertains to subgroup analyses of trials which both failed to achieve their primary end points, those being mortality for the TORCH trial and decline of $\mathrm{FEV}_{1}$ for the UPLIFT trial. These data should therefore be interpreted with caution. Indeed, as indicated above, the results of interest here do not correspond to the primary end points of the study. Also other methodological concerns of subgroup analyses are relevant here. Moreover, as far as the conclusions regarding GOLD stage II are concerned, the patients studied in the abovementioned studies were symptomatic patients who were followed by pulmonary specialists. They also had relatively advanced stage II disease $\left(\mathrm{FEV}_{1} 59 \pm 7 \%\right.$ and $59 \pm 6 \%$ predicted, respectively). They may therefore not be representative of the average (asymptomatic) GOLD stage II patient encountered in general practice. Finally, none of these studies addressed the cost-effectiveness of treatment. In considering treatment of early stages of COPD, this may become an important issue. For long-term treatment, safety would without question also be an important consideration. On the basis of the $\mathrm{TORCH}^{9}$ and UPLIFT data, ${ }^{11}$ the fixed combination of salmeterol, and fluticasone, and tiotropium appeared to be safe over periods of 3 and 4 years, respectively, in the sense that no major cardiovascular or other side effects appeared to occur. ${ }^{9} 24$ One observed side effect of treatments that include inhaled corticosteroids is a higher reported incidence of pneumonia. ${ }^{9}$ This problem, if borne out by additional studies, could relate to alterations in local mucosal immune mechanisms that will warrant further investigation. No data are available for longer term treatment periods and the currently available data do not allow us to conclude which treatment would be the more effective as early treatment: LAMAs, LABAs, inhaled corticosteroids or fixed combinations of LABAs and inhaled corticosteroids.

A final argument in favour of early treatment of COPD is the prevalence of co-morbidities that also start early in the disease. ${ }^{25}$ Indeed, COPD is associated with a number of co-morbidities including deconditioning, diabetes, cardiovascular disease, osteoporosis, gastro-oesophageal reflux disease and depression. ${ }^{26} 27$ The exact pathophysiology of these co-morbidities is not clearly understood, but systemic inflammation and particularly physical inactivity are likely causes. Inactivity is present from early in the disease onwards (GOLD stage I and II). ${ }^{28-30}$ It has been proposed that physical inactivity and deconditioning are direct consequences of dynamic hyperinflation during exercise. ${ }^{4}$ Dynamic hyperinflation occurs because of reduced lung elastic recoil, and increased airway resistance. ${ }^{31}$ By increasing operational lung volumes, dynamic hyperinflation increases elastic work of breathing and forces patients towards thresholds of 
exercise limitation determined by their respiratory system mechanics. ${ }^{32}$ There is evidence for dynamic hyperinflation being present from early in the disease, even in GOLD stage $\mathrm{I}^{33}$ Whether early treatment reduces inactivity and, hence, co-morbidities is not known at present. A formal rehabilitation programme was shown to increase activity levels, as measured by daily walking time, ${ }^{34}$ but the effect was relatively limited. In patients with severe COPD, exercise training was shown to decrease ventilatory requirement and exercise-induced hyperinflation, ${ }^{35}$ but as yet it is not known whether these effects would be present in earlier disease. As we focus more on earlier COPD we must consider whether encouraging healthy lifestyles with or without pharmacotherapy could be more cost-effective than formal rehabilitation programmes. Clearly more research is needed on the important question of whether current treatments of COPD improve activity levels and whether early treatment reduces the prevalence of co-morbidities of the disease.

\section{IMPLICATIONS FOR THE PROGRESSIVE LOSS IN PULMONARY FUNCTION IN COPD}

The classical concept of disease progression in COPD is illustrated in the well known figure published by Fletcher and Peto in $1977 .{ }^{23}$ These investigators plotted $\mathrm{FEV}_{1}$ as a percentage of the value at age 25 on the $y$-axis against time on the $x$-axis, presupposing that the rate of loss of $\mathrm{FEV}_{1}$ accelerates over time, becoming faster with more severe disease. Figure 3 shows the curve for smokers from the Fletcher Peto study (dashed line), modified and plotted as a percentage of the age-predicted value on the $y$-axis. Data from the TORCH ${ }^{9} 1019$ and UPLIFT ${ }^{11} 1720$ studies have been plotted on the same axes. This figure puts published data in perspective, compared with the overall clinical course of COPD. Also, it shows that patients in clinical trials with different GOLD stages can be of a similar age, contrary to the belief that those with GOLD stage II would be significantly younger. Figure 4 shows data from the TORCH $^{9} 1019$ and UPLIFT ${ }^{11} 1720$ studies separated according to GOLD stages II, III and IV. This figure shows that the rate of decline of $\mathrm{FEV}_{1}$ is somewhat faster in GOLD stage II patients. However, an intriguing observation from this figure is the fact that former smokers, of similar ages, with different degrees of COPD severity (defined by lung function impairment), on various types of maintenance treatment for COPD, have remarkably similar rates of decline of $\mathrm{FEV}_{1}$. One is led to suspect that their $\mathrm{FEV}_{1}$ at a given age may be determined more by their initial level of pulmonary function (say at age 25) than by the rate of change over time (ie, by the intercept rather than the slope of the $\mathrm{FEV}_{1}$-time curve). This observation has obvious implications for the role of low lung function in early life on clinical manifestations of chronic lung disease in later life. Clearly, the concept of disease progression in COPD as expressed in terms of $\mathrm{FEV}_{1}$ needs to be reconsidered. Rather than seeing an accelerated rate of decline of $\mathrm{FEV}_{1}$ with more severe disease, both the TORCH and UPLIFT studies show convincingly that decline in pulmonary function occurs at a faster rate in the early stages of the disease. The findings from these two studies are remarkably consistent, with the rate of decline of $\mathrm{FEV}_{1}$ being $\sim 50 \mathrm{ml} /$ year in GOLD stage II and $\sim 30 \mathrm{ml} /$ year in GOLD stage IV. If, indeed, most of the decline occurs early in the disease, then early intervention is necessary to prevent progressive functional deterioration and to maintain organ function at a higher level. Although the present concept contrasts with conventional thinking, it is supported by recent data (see above) and, furthermore, is consistent with

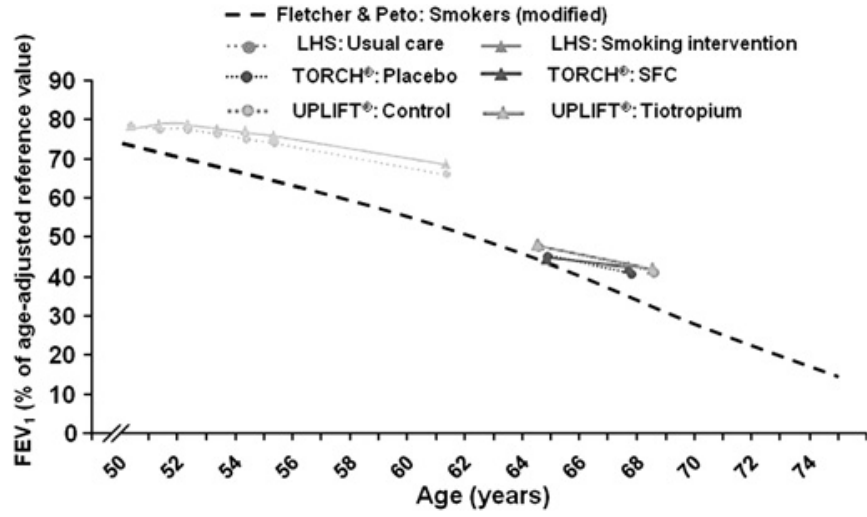

Figure 3 Current evidence of disease progression in chronic obstructive pulmonary disease (COPD) expressed in terms of the decline in forced expiratory volume in $1 \mathrm{~s}\left(\mathrm{FEV}_{1}\right)$ over time. The curve for smokers from the study of Fletcher and Peto ${ }^{23}$ is shown, along with data for treatment and placebo groups in the Lung Health Study, ${ }^{6}$ as well as all subjects in the TORCH ${ }^{9}$ and UPLIFT ${ }^{10}$ clinical trials. Additional data are one file with Boehringer Ingelheim and GlaxoSmithKline and is shown with permission.

studies of organ deterioration in other chronic disease, such as the decline in glomerular filtration rate after acute myocardial infarction $^{36}$ or in patients undergoing peritoneal dialysis and haemodialysis. ${ }^{37}$

\section{IMPLICATIONS FOR EARLY TREATMENT AND FUTURE RESEARCH}

What are the implications of the data summarised above for early treatment of COPD? Do we now have sufficient evidence to propose earlier treatment of patients, who currently come to our clinics markedly impaired and receive medication in the later stages of the disease? As yet we do not have irrefutable evidence that early detection and early treatment are mandatory. However, we do have accumulating evidence that outcome variables in patients with GOLD stage II improve substantially,

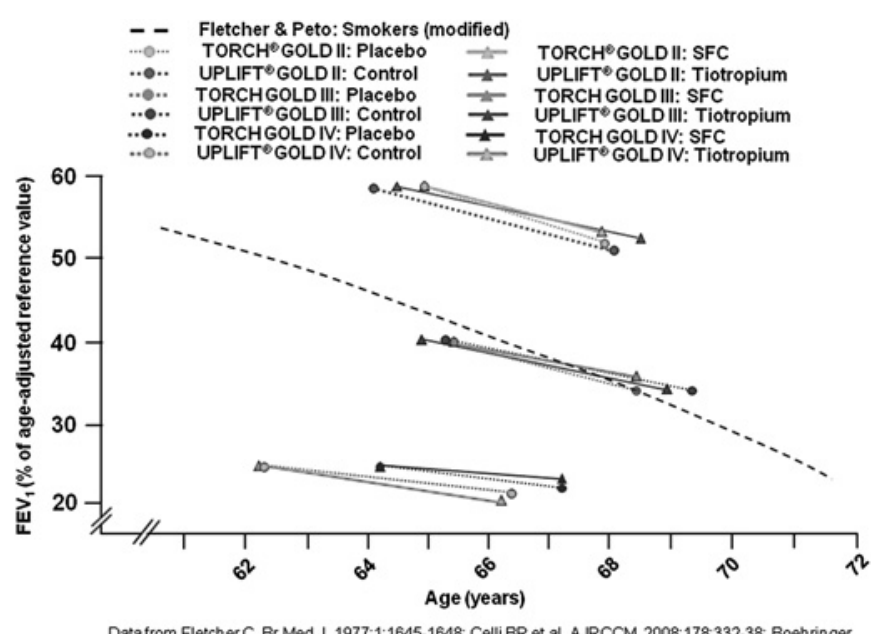

Datafrom Fletcher C. Br Med J. 1977:1:1645-1648; Celli BR et al. A.JRCCM 2008;178:332-38; Boehringer Ingetheim, data on file; GlaxoSmith Kline, data on file.

Figure 4 Current evidence of disease progression in chronic obstructive pulmonary disease (COPD) expressed in terms of the decline in forced expiratory volume in $1 \mathrm{~s}\left(\mathrm{FEV}_{1}\right)$ over time. The curve for smokers from the study of Fletcher and Peto ${ }^{23}$ is shown, along with data for treatment and placebo groups in TORCH ${ }^{9} 10{ }^{19}$ and UPLIFT ${ }^{11} 1720$ clinical trials. The data have been separated according to GOLD (Global Initiative for Chronic Obstructive Pulmonary Disease) stages II, III and IV. 
and no less than in patients in GOLD stage III and IV, with commonly prescribed medications such as fixed combinations of LABA/inhaled corticosteroid and long-acting anticholinergics. These improvements relate to pulmonary physiology (lung function), health status and patient-reported outcomes (exacerbations). The most compelling data come from subgroup analyses of large long-term trials in which outcomes in GOLD stage II patients were not the primary outcomes. However, one smaller scale study, specifically designed for GOLD stage II patients, has shown similar results. ${ }^{18}$ So at present we can say with reasonable certainty that we are able to produce clinical improvements in GOLD stage II patients or patients with early disease.

Should we aim to improve them for any other reason than improving their symptoms? There are suggestions that not only do we improve outcomes, but we can also modify the progression of the disease in the early stages - that is, the stages in which the disease progresses most rapidly. What is still missing to make a compelling argument for early detection is a convincing demonstration that withholding early treatment has deleterious consequences for the patients involved. This could be a demonstration of a larger and persistent pulmonary function deficit in patients not receiving early treatment, a persistent reduction in health status, a persistently higher exacerbation rate or faster progression of the disease. If such detrimental effects of not starting treatment early can be demonstrated, then we will have a substantially more convincing case for earlier treatment than we presently have.

Competing interests $\mathrm{MD}$ received consulting fees from Boehringer Ingelheim, Pfizer, GlaxoSmithKline, Nycomed and AstraZeneca, lecture fees from Boehringer Ingelheim, Pfizer and Novartis, and grant support from AstraZeneca. CBC has received consulting fees from Boehringer Ingelheim, Dey Pharmaceuticals, Pfizer and Forest, lecture fees from AstraZeneca, Boehringer Ingelheim, Dey Pharmaceuticals and Pfizer, and grant support from Boehringer Ingelheim, CSL-Behring and Pfizer.

Ethics approval This study was conducted with the approval of the ethics committee of the appropriate university hospitals.

Provenance and peer review Not commissioned; externally peer reviewed.

\section{REFERENCES}

1. Buist AS, McBurnie MA, Vollmer WM, et al. International variation in the prevalence of COPD (the BOLD Study): a population-based prevalence study. Lancet 2007:370:741-50.

2. Coxson HO, Rogers RM, Whittall KP, et al. A quantification of the lung surface area in emphysema using computed tomography. Am J Respir Crit Care Med 1999;159:851-6.

3. Hasegawa M, Nasuhara $Y$, Onodera $Y$, et al. Airflow limitation and airway dimensions in chronic obstructive pulmonary disease. Am J Respir Crit Care Med 2006;173:1309-15.

4. Cooper CB. The connection between chronic obstructive pulmonary disease symptoms and hyperinflation and its impact on exercise and function. Am J Med 2006;119:21-31.

5. Oga T, Nishimura K, Tsukino M, et al. Exercise capacity deterioration in patients with COPD: Iongitudinal evaluation over 5 years. Chest 2005;128:62-9.

6. Anthonisen NR, Connett JE, Murray RP. Smoking and lung function of Lung Health Study participants after 11 years. Am J Respir Crit Care Med 2002;166:675-9.

7. Anthonisen NR, Skeans MA, Wise RA, et al. The effects of a smoking cessation intervention on 14.5-year mortality: a randomized clinical trial. Ann Intern Med 2005;142:233-9.

8. Donaldson GC, Seemungal TA, Bhowmik A, et al. Relationship between exacerbation frequency and lung function decline in chronic obstructive pulmonary disease. Thorax 2002; 57:847-52.

9. Celli BR, Thomas NE, Anderson JA, et al. Effect of pharmacotherapy on rate of decline of lung function in chronic obstructive pulmonary disease: results from the TORCH study. Am J Respir Crit Care Med 2008;178:332-8.
10. Calverley PM, Anderson JA, Celli B, et al. Salmeterol and fluticasone propionate and survival in chronic obstructive pulmonary disease. $N$ Engl $\mathrm{J} \mathrm{Med}$ 2007;356:775-89.

11. Tashkin DP, Celli B, Senn S, et al. A 4-year trial of tiotropium in chronic obstructive pulmonary disease. N Engl J Med 2008;359:1543-54.

12. Troosters T, Celli B, Lystig T, et al. Tiotropium as a first maintenance drug in COPD: secondary analysis of the UPLIFT trial. Eur Respir J 2010;36:65-73.

13. Lung Health Study Research Group. Effect of inhaled triamcinolone on the decline in pulmonary function in chronic obstructive pulmonary disease. $N$ Engl J Med 2000;343:1902-9.

14. Burge PS, Calverley PM, Jones PW, et al. Randomised, double blind, placebo controlled study of fluticasone propionate in patients with moderate to severe chronic obstructive pulmonary disease: the ISOLDE trial. BMJ 2000;320:1297-303.

15. Pauwels RA, Lofdahl CG, Laitinen LA, et al. Long-term treatment with inhaled budesonide in persons with mild chronic obstructive pulmonary disease who continue smoking. European Respiratory Society Study on Chronic Obstructive Pulmonary Disease. N Engl J Med 1999;340:1948-53.

16. Vestbo J, Sorensen $T$, Lange $P$, et al. Long-term effect of inhaled budesonide in mild and moderate chronic obstructive pulmonary disease: a randomised controlled trial. Lancet 1999;353:1819-23.

17. Decramer $\mathbf{M}$, Celli B, Kesten $\mathrm{S}$, et al. Effects of tiotropium on outcomes in patients with moderate chronic obstructive pulmonary disease (UPLIFT): a prespecified subgroup analysis of a randomised controlled trial. Lancet 2009;374:1171-8.

18. Johansson G, Lindberg A, Romberg K, et al. Bronchodilator efficacy of tiotropium in patients with mild to moderate COPD. Prim Care Respir J 2008:17:169-75.

19. Jenkins CR, Jones PW, Calverley PM, et al. Efficacy of salmeterol/fluticasone propionate by GOLD stage of chronic obstructive pulmonary disease: analysis from the randomised, placebo-controlled TORCH study. Respir Res 2009;10:59.

20. Decramer M, Celli B, Tashkin DP, et al. Clinical trial design considerations in assessing long-term functional impacts of tiotropium in COPD: the UPLIFT trial. COPD 2004;1:303-12.

21. Beaucage $\mathbf{F}$, Fremault $A$, Janssens $W$, et al. FEV1 decline in COPD patients according to severity stages. Am J Respir Crit Care Med 2008;177:A401 (abstract).

22. Scanlon PD, Connett JE, Waller LA, et al. Smoking cessation and lung function in mild-to-moderate chronic obstructive pulmonary disease. The Lung Health Study. Am J Respir Crit Care Med 2000;161:381-90.

23. Fletcher C, Peto R. The natural history of chronic airflow obstruction. Br Med J 1977:1:1645-8.

24. Celli B, Decramer M, Kesten S, et al. Mortality in the 4-year trial of tiotropium (UPLIFT) in patients with chronic obstructive pulmonary disease. Am J Respir Crit Care Med 2009;180:948-55.

25. Decramer M, Rennard S, Troosters T, et al. COPD as a lung disease with systemic consequences-clinical impact, mechanisms, and potential for early intervention. COPD 2008:5:235-56

26. Fabbri LM, Rabe KF. From COPD to chronic systemic inflammatory syndrome? Lancet 2007:370:797-9.

27. Fabbri LM, Luppi F, Beghe B, et al. Complex chronic comorbidities of COPD. Eur Respir J 2008;31:204-12.

28. Pitta F, Troosters T, Spruit MA, et al. Characteristics of physical activities in daily life in chronic obstructive pulmonary disease. Am J Respir Crit Care Med 2005;171:972-7

29. Watz H, Waschki B, Boehme C, et al. Extrapulmonary effects of chronic obstructive pulmonary disease on physical activity: a cross-sectional study. Am J Respir Crit Care Med 2008;177:743-51.

30. Watz H, Waschki B, Meyer T, et al. Physical activity in patients with COPD. Eur Respir J 2009;33:262-72.

31. Cooper CB, Dransfield M. Primary care of the patient with chronic obstructive pulmonary disease-part 4: understanding the clinical manifestations of a progressive disease. Am J Med 2008;121:S33-45

32. O'Donnell DE, Revill SM, Webb KA. Dynamic hyperinflation and exercise intolerance in chronic obstructive pulmonary disease. Am J Respir Crit Care Med 2001;164:770-7

33. Ofir D, Laveneziana $\mathrm{P}$, Webb KA, et al. Mechanisms of dyspnea during cycle exercise in symptomatic patients with GOLD stage I chronic obstructive pulmonary disease. Am J Respir Crit Care Med 2008;177:622-9.

34. Pitta F, Troosters T, Probst VS, et al. Are patients with COPD more active after pulmonary rehabilitation? Chest 2008;134:273-80.

35. Porszasz J, Emtner $\mathrm{M}$, Goto $\mathrm{S}$, et al. Exercise training decreases ventilatory requirements and exercise-induced hyperinflation at submaximal intensities in patients with COPD. Chest 2005;128:2025-34.

36. Hillege HL, van Gilst WH, van Veldhuisen DJ, et al. Accelerated decline and prognostic impact of renal function after myocardial infarction and the benefits of ACE inhibition: the CATS randomized trial. Eur Heart J 2003;24:412-20.

37. Jansen MA, Hart AA, Korevaar JC, et al. Predictors of the rate of decline of residual renal function in incident dialysis patients. Kidney Int 2002;62:1046-53. 